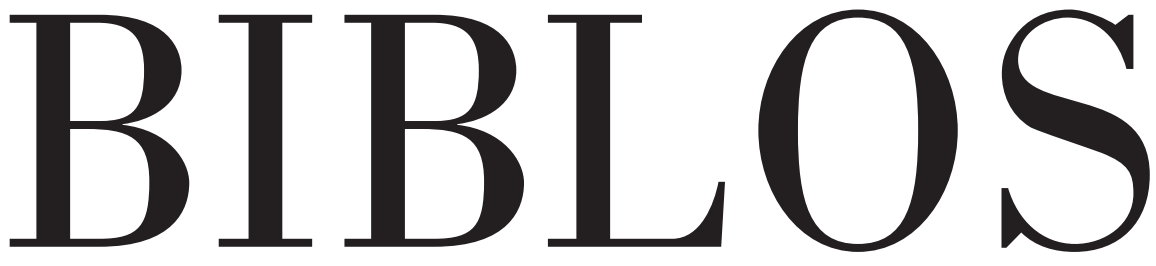

Revista da Faculdade de Letras da Universidade de Coimbra

NÚMERO 5, 2019

3. ${ }^{\text {a SÉRIE }}$ 


\section{DIRETOR}

Rui Gama | diretor.letras@fl.uc.pt

Faculdade de Letras da Universidade de Coimbra

\section{DIREÇÃO EXECUTIVA}

COORDENADORA

Rita Marnoto | rmarnoto@fl.uc.pt

Faculdade de Letras da Universidade de Coimbra

ADJUNTOS:

António Campar de Almeida | campar@ci.uc.pt Faculdade de Letras da Universidade de Coimbra Isabel Mota | ifmota@fl.uc.pt

Faculdade de Letras da Universidade de Coimbra Beatriz Marques | breatrizmarques@ci.uc.pt Faculdade de Letras da Universidade de Coimbra SECRETÁRIA:

Carla Rosa|gapci@fl.uc.pt

Faculdade de Letras da Universidade de Coimbra

\section{CONSELHO CIENTÍFICO}

Abel Barros Baptista|abelbb2@gmail.com Universidade Nova de Lisboa

Agustín Serrano de Haro|agustin.serrano@cchs.csic.es Universidade Complutense de Madrid

Albano Figueiredo | afigueiredo@fl.uc.pt Faculdade de Letras da Universidade de Coimbra Ana Gabriela Macedo | gabrielam@ilch.uminho.pt Universidade do Minho

António Manuel Martins | amm.fluc@gmail.com Faculdade de Letras da Universidade de Coimbr António Martins da Silva | ams@ci.uc.pt Faculdade de Letras da Universidade de Coimbra António Sousa Ribeiro | asr@ces.uc.pt Faculdade de Letras da Universidade de Coimbra Ataliba Teixeira de Castilho | ataliba@uol.com.br Universidade de São Paul

Carlos Reis|c.a.reis@mail.telepac.pt

Faculdade de Letras da Universidade de Coimbr

Christian Möckel | MoeckelC@philosophie.hu-berlin.de Universidade Humboldt de Berlim

Diederik Meijer |d.j.w.meijer@arch.leidenuniv.n Universidade de Leiden

Domingo González Lopo | domingoluis.gonzalez@usc.es Universidade de Santiago de Compostel

Elias Sanz Casado | elias@bib.uc3m.es

Universidade Carlos III de Madrid

Étienne Nel | etienne.nel@otago.ac.nz

Universidade de Otago

Fátima Velez de Castro | velezcastro@fl.uc.p

Faculdade de Letras da Universidade de Coimbra

Fernanda Delgado Cravidáo | cravidao@fl.uc.pt

Faculdade de Letras da Universidade de Coimbra
Fernando José de Almeida Catroga | fcatroga@hotmail.com Faculdade de Letras da Universidade de Coimbra

Francisco Javier Pizarro Gómez | jpizarro@unex.es

Universidade de Extremadura, Cáceres

Francisco Oliveira | foliveir@fl.uc.pt

Faculdade de Letras da Universidade de Coimbra

Gilles Gauthier | gilles.gauthier@com.ulaval.ca Universidade do Québec, Montréal

Gustavo Cardoso | gustavo.leitao.cardoso@gmail.com Instituto Superior de Ciências do Trabalho e da Empresa -

Instituto Universitário de Lisboa

Isabel Vargues | ivargues@fl.uc.pt

Faculdade de Letras da Universidade de Coimbra

Joāo Lima de Sant'Anna Neto | j1sn57@uol.com.br Universidade Estadual Paulist

Jordi Tresseras | gestiocultural@ub.edu

Universidade de Barcelon

Jorge de Alarcáo | jorge.alarcao@gmail.com

Faculdade de Letras da Universidade de Coimbra

José Antonio Frías | frias@usal.es

Universidade de Salamanca

José Augusto Cardoso Bernardes | augusto@ci.uc.pt Faculdade de Letras da Universidade de Coimbra

José Augusto Guimarães | guima@marilia.unesp.br Universidade Estadual Paulista "Júlio de Mesquita Filho"

Lucinda Fonseca | fonseca-maria@campus.ul.pt Universidade de Lisboa

Lúcio Sobral da Cunha | luciogeo@ci.uc.pt Faculdade de Letras da Universidade de Coimbra

Luísa Trindade | trindade.luisa@gmail.com Faculdade de Letras da Universidade de Coimbra

Marc Lits |marc.lits@uclouvain.be

Universidade Católica de Louvain

Márcio Moraes Valença| marciovalenca10@gmail.com Universidade Federal do Rio Grande do Nort

Maria da Graça Simóes | gsimoes@uc.pt

Faculdade de Letras da Universidade de Coimbra

Maria del Carmen Paredes | paredes@usal.es

Universidade de Salamanca

Maria Helena da Cruz Coelho | coelhomh@gmail.com

Faculdade de Letras da Universidade de Coimbra

Miguel Bandeira | bandeira@ics.uminho.pt

Universidade do Minh

Pavel Szobi| pavel.szobi@vse.cz

Universidade de Economia de Praga

Pedro Aullón de Haro | p.aullondeharo@gmail.com

Universidade de Alicante

Peter Andersen | peter.andersen@uib.no

Universidade de Bergen

Roberto Gigliucci | roberto.gigliucci@uniromal.it

Universidade de Roma, La Sapienza

Rui Pedro Juliăo | rpj@fcsh.unl.pt

Universidade Nova de Lisboa

Soterraña Aguirre Rincón | sote.aguirre@gmail.com

Universidade de Valladolid

Teresa Seruya | t.seruya@letras.ulisboa.pt

Universidade de Lisboa

Thomas Earle | thomas.earle@mod-langs.ox.ac.uk

St. Peter's College, Oxford

Viriato Soromenho Marques | viriatosmarques@netcabo.pt Universidade de Lisboa

Vítor Oliveira Jorge | vojorge@clix.pt

Universidade do Porto

\section{REVISÃO DE INGLÊS}

Rosa Bandeirinha, Samuel Alexandre
REVISÃO DE PROVAS

Carla Rosa 


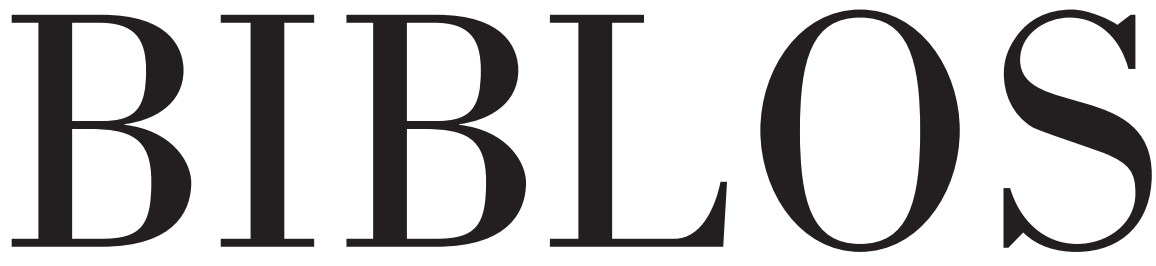

Revista da Faculdade de Letras da Universidade de Coimbra

\section{5 \\ FALSIFICAÇÕES}

NÚMERO 5, 2019

3. ${ }^{\text {a }}$ SÉRIE 


\author{
EDIÇÃO \\ Imprensa da Universidade de Coimbra \\ Rua da Ilha, 1 - 3000-214 Coimbra \\ Email: imprensa@uc.pt \\ URL: http://www.uc.pt/imprensa_uc \\ Vendas online: http://livrariadaimprensa.uc.pt \\ DESIGN \\ Carlos Costa \\ IMPRESSÃO E ACABAMENTO \\ ISSN \\ $0870-4112$ \\ ISBN Digital \\ 2183-7139 \\ DOI \\ https://doi.org/10.14195/0870-4112_3-5 \\ DEPÓSITO LEGAL \\ $1401 / 82$ \\ PERIODICIDADE Anual • TIRAGEM $200 \mathrm{ex}$.
}

Biblos. Revista da Faculdade de Letras da Universidade de Coimbra está indexada no European Reference Index for the Humanities (ERIH Plus).

A Biblos está na SCOPUS e WEBof SCIENCE

HTTPS://IMPACTUM.UC.PT/EN/CONTENT/REVISTA?TID=28707\&ID=28707

HTTP://WWW.UC.PT/FLUC/INVESTIGACAO/BIBLOS

\author{
(C) OUTUBRO, 2017 \\ IMPRENSA DA UNIVERSIDADE DE COIMBRA \\ FACULDADE DE LETRAS DA UNIVERSIDADE DE COIMBRA
}

PROPRIEDADE • CONTACTOS • SEDE DE REDAÇÃO

Biblos. Revista da Faculdade de Letras da Universidade de Coimbra

Gabinete de Comunicação e Imagem. Faculdade de Letras da Universidade de Coimbra

Largo da Porta Férrea • 3004-530 Coimbra (Portugal)

Telef. 239859984 • gapci@fl.uc.pt 


\section{SUMÁRIO}

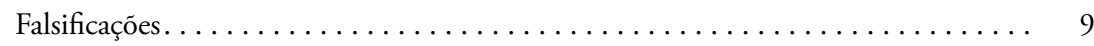

As falsificaçôes e o bem-estar . . . . . . . . . . . . . . . . . 13

Carlos Pimenta

Música Contrafeita. A partitura como autenticidade falsa . . . . . . . . . . . 35

Margarida Teixeira Neves

A cópia, a Moda e a propriedade industrial $\ldots \ldots \ldots \ldots \ldots \ldots \ldots \ldots \ldots \ldots \ldots \ldots \ldots$

Humberto Pinheiro Lopes

Alguns contributos das ciências para a investigação de obras de arte . . . . . . 71

Francisco Paulo de Sá Campos Gil, Lídia Maria Gil Catarino

Verità o falsificazione? Gli Alleati e la mafia sulle pagine dell' Ora (1958-1963) . . . . 105

Ciro Dovizio

Stefan Zweig, Romain Rolland e a Grande Guerra . . . . . . . . . . . . . . 125

Maria de Fátima Gil

“Que lindo cenário!” Trasformazione della facciata nazionale durante l'Estado Novo 147 Agnese Soffritti

"Nemine discrepante": Agostinho Barbosa (1590-1649), estudante da Universidade de Coimbra, erudito lexicógrafo, canonista difamado?. . . . . . . . . . . . . . 173

Paola Nestola

Eruditos, falsificações e miliários

Vasco Gil Mantas 
Uma epígrafe inventada por Frei Bernardo de Brito

José d'Encarnação

\section{Cruzamentos}

A dúvida

Miguel Miranda.

\section{Entrevista}

Falsificação e artes: chuvas oblíquas.

Nuno Júdice

\section{Recensóes}

Jorun Poettering. Migrating merchants. Trade, nation, and religion in seventeenth-century Hamburg and Portugal

Jaime Ricardo Gouveia .

Stefano Pittaluga. Il falso letterario dall'Antichità al Rinascimento 285

Miguel Monteiro

Ana Marques Gastão; Sérgio Nazar David. O olho e a mão . .

Sofia Moreira

\section{Próximo número}

Arquétipo 


\title{
UMA EPÍGRAFE INVENTADA POR FREI BERNARDO DE BRITO
}

\section{A Roman inscription that Father Bernardo de Brito fabricated}

\author{
JOSÉ D'ENCARNAÇÃO \\ jde@fl.uc.pt
}

Faculdade de Letras da Universidade de Coimbra

ORCID: 0000-0002-9090-557x

DOI

https://doi.org/10.14195/0870-4112_3-5_10

Recebido em setembro de 2018

Aprovado em novembro de 2018

Biblos. Número 5, 2019 • 3.a Série

pp. $233-251$ 


\title{
JOSÉ D’ENCARNAÇÃO
}

\section{RESUMO.}

Num dos capítulos da sua monumental obra Monarchia Lusytana, em que dá conta da campanha do procônsul romano Décimo Júnio Bruto para submeter os povos do Ocidente peninsular, frei Bernardo de Brito mostra que uma batalha travada perto do rio Távora (onde há, de facto, muitos vestígios romanos) não teve vitória fácil. E para o demonstrar, salientando a bravura dos "Portugueses", inventou os epitáfios de dois importantes membros das tropas romanas: um signifer e um eques. É o epitáfio deste último que se analisa do ponto de vista epigráfico e literário.

Palavras-chave: Bernardo de Brito; Invenção de inscriçốes; Guerras lusitanas; Décimo Júnio Bruto; Moimenta da Beira.

\begin{abstract}
.
In one of the chapters of his monumental book Monarchia Lusytana, which describes Roman proconsul Decimus Iunius Brutus' military campaign against the peoples that lived in Western Hispania, the author, Bernardo de Brito, shows that the Romans fought a very difficult battle near the Távora river (a region with many Roman remains). So, to demonstrate and highlight the bravery of the 'Portuguese' troops, he forged the epitaphs of two important Roman legionaries killed in battle: a signifer and an eques. We aim to study the epitaph of the eques (CIL II 55*), giving special attention to its epigraphic and literary aspects.
\end{abstract}

Keywords: Bernardo de Brito; Forgery of inscriptions; Lusitanian wars; Decimus Iunius Brutus; Moimenta da Beira. 


\section{O TESTEMUNHO DE FREI BERNARDO DE BRITO}

Recorde-se que é frei Bernardo de Brito quem afirma ter encontrado as actas de umas cortes em Lamego, segundo as quais, pelo que nelas vinha exarado em relação a regras de sucessão ao trono, Filipe II de Espanha teria de ser considerado, de facto, um usurpador.

Nascera o frade em 1569, viria a falecer em 1617, em pleno período, portanto, da dominação filipina em Portugal, e a sua obra Monarquia Lusitana começou a ser publicada em 1597. Escreve-se no frontispício da I parte que nela se "contêm as histórias de Portugal, desde a criação do mundo até o nascimento de Nosso Senhor Jesus Cristo"'.

Numa época em que se começava seriamente a pensar que se caíra num logro e que, afinal, as promessas feitas nas Cortes de Tomar de 1581 não estavam a ser cumpridas e cada vez se percebia melhor que nunca viriam a sê-lo e que, por outro lado, a proposta de a Corte vir para Lisboa, por mais elogios que se fizessem à cidade (Encarnação, 1969), não estava nos planos de Filipe III, pressionado pelos interesses de Sevilha, o espírito nacionalista deu em vir ao de cima. Urgia, pois, incentivá-lo, nomeadamente dando a conhecer tempos passados em que os "portugueses" se haviam corajosamente batido contra o inimigo que os queria subjugar.

Uma dessas lutas, perpetuada pelos historiadores antigos, foi a que o procônsul Décimo Júnio Bruto, nomeado governador da Hispânia Ulterior em 138 a. C., travou contra os habitantes do território hoje nacional e que a literatura de então se apressou a chamar de "portugueses" ou mesmo "lusitanos" dando a este vocábulo o significado daqueles. Ainda que o texto de Jorge de Alarcão (1988b: 22-23) seja de síntese, o certo é que nos elucida bastante acerca de um aspecto importante dessa gesta de Décimo Júnio Bruto: é que dela escreveu Estrabão, Apiano e até Orósio, que afirma ter o general derrotado um exército de 60000 calaicos que tinham vindo socorrer os Lusitanos, façanha que lhe valeu o título

Consultou-se essa I parte, na edição de Lisboa, datada, por lapso, de 1365 (por 1865). Tem na BNP a cota: L/14591 e encontra-se acessível em http://purl.pt/13984/3/\#/196, consultado a 15-09-2018. Nas citaçóes, actualizou-se a grafia. 
de Callaicus. Ou seja, a sua fama e a da bravura dos seus homens perpetuou-se. Além de ter fortificado Olisipo, narra-se que fez de Moron, nas margens do rio Tejo, a sua base de operaçôes. Aceita-se que o seu percurso terá sido pela zona litoral, seguindo o que virá a ser, mais tarde, a estrada que ligará Olisipo a Bracara Augusta. Esse, portanto, um período assaz propício a fantasias e mais do que apto a nele se incluírem feitos heróicos dos povos que estavam a ser atacados.

Escolheu-o, pois, frei Bernardo de Brito e vamos, por conseguinte, seguir o que nos conta.

Interessa-nos, de modo especial, o capítulo XIV, que trata "Da jornada que Bruto fez contra os moradores da Beira e como tomou por assento da guerra a cidade chamada Moro, e do sítio onde esteve, com outras cousas tocantes a esta conquista" (p. 329).

Chegou Bruto às margens do Távora, cuja riqueza piscícola frei Bernardo de Brito salienta, também por ali haver, por exemplo, "pasto para os cavalos". Bruto aí "se deteve alguns dias, para dar alívio aos soldados" (ibidem).

Tendo, pois, enviado alguns dos seus homens em reconhecimento dos arredores, sucedeu que eles foram mal recebidos pela populaçáo, tendo acabado por deixar "bom número de companheiros mortos, em castigo de se atreverem tanto". Sucedeu, além disso, que Bruto se apercebeu estar o inimigo a ajuntar forças e, por tal motivo, escreve frei Bernardo de Brito, sentiu-se na obrigação de dar batalha contra os Portugueses, "antes que o mal fosse maior" (p. 330). Trava-se dura luta, que a custo os Romanos vencem e é na sequência dela que vêm as inscrições dos mortos mais ilustres: um signifer (porta-estandarte) e um cavaleiro.

Explicita-se de seguida que teve o Procônsul os seus arraiais

onde agora vemos uma Ermida dedicada em louvor de Sáo Joáo Bautista, perto do lugar de Vide, onde se descobriram há mui pouco tempo alguns letreiros romanos, e sinais de armas antigas, das quais eu vi umas lâminas de couraças e uma espora de prata feita por um modo bem diferente do que se costuma no tempo de agora. Os letreiros nấo vi todos, porque os lavradores, que ali vinham cavar, com esperança de achar algum dinheiro, fazendo pouco caso deles, quebravam as pedras, ou as levavam para tapumes das vinhas que há ao redor; mas de três que pude ver coligi a mor parte 
do que tenho contado, uma das quais tinha esculpidas estas letras assaz barbaramente e com pouca curiosidade do que as entalhou nela. (p. 330)

É o suposto epitáfio do signifer Quinto Fortunato Capuano (CIL II 54*).

Não se fica por aqui:

"Outra pedra mais pequena e melhor lavrada vi no mesmo lugar, que servia de assento dentro na Ermida velha de S. João e dizia deste modo" (Fig. 1), cuja explanação dá de imediato (Fig. 2):

Quer dizer: Memória consagrada aos deuses dos defuntos. Gaio Possidónio, cavaleiro romano, morador no monte Viminal, arremeteu com seu cavalo aos Bárbaros, que levavam já os romanos de vencida, morreu pelejando valerosamente; e Décio Júnio Bruto, por respeito de amor, e benevolência, trabalhou que se lhe pusesse aqui esta sepultura. Seja-te a terra leve. (p. 331)

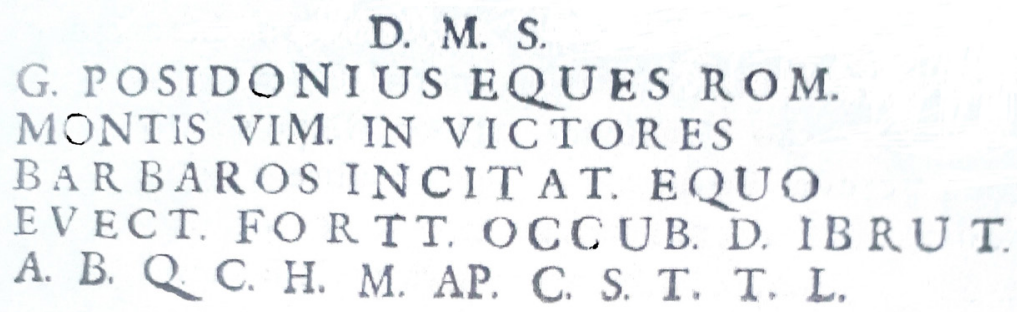

Fig. 1

E traz, depois, uma outra informaçáo com tal profusão de pormenores, como se, na realidade, o que ele conta tenha verdadeiramente acontecido:

Outra pedra se achou ali pouco maior que uma mão, a qual eu tenho na minha, e a estimo pela muita fineza que tem, e por ser de um jaspe mui gracioso, e inda que estava cheia de letras, como eram hebraicas, e eu naquele tempo não tinha inda tanta notícia desta língua como agora 
tenho, imaginava que devia ser algum segredo de antiguidade notável. Mas depois que aprendi a fala hebreia, e vi o que tinha, desenganei-me do que cuidava e entendi ser aquilo cousa mais moderna, e do tempo que o imperador Vespasiano destruiu Jerusalém e mandou muitos judeus desterrados a Espanha. (p. 331)

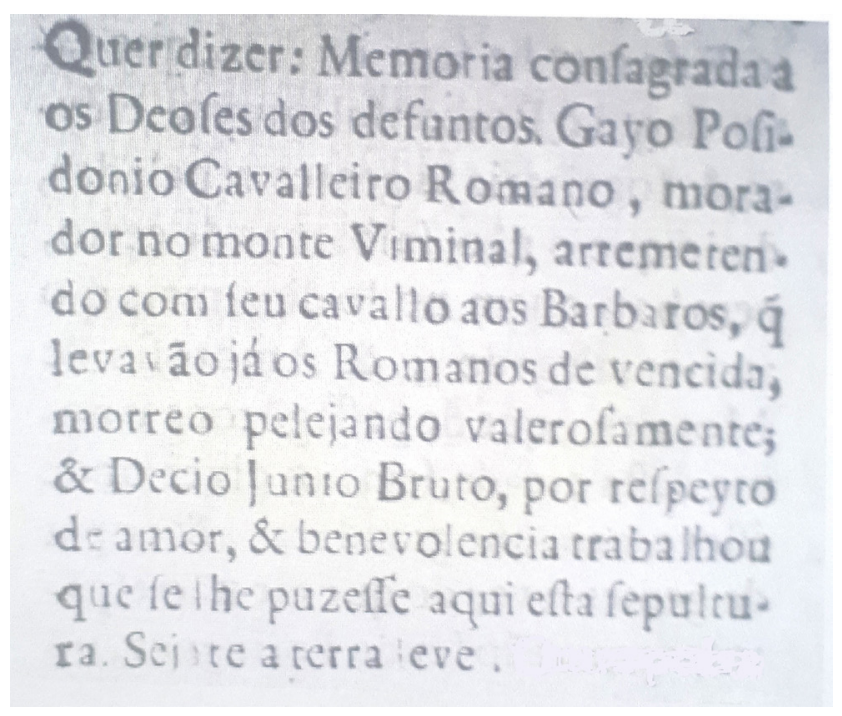

Fig. 2

Fiquemo-nos por aqui na narração britiana, embora a referência a uma possível inscrição hebraica não seja, de facto, despicienda de todo, atendendo ao facto de ter sido a zona habitada por cristáos-novos, na sequência das perseguiçôes aos Judeus do século XVI e não, como se compreende, devido a qualquer expulsão para a Hispânia ao tempo de Vespasiano. Poderá acrescentar-se, no entanto, que ainda há referência a uma epígrafe BONO REIPVBLICAE NATO, levada para Vide e incorporada na parede "de uma ermida que se fez em louvor de S. Sebastiâo” (p. 332).

Dessa zona beirã partiu Décimo Júnio Bruto para Moro, "uma cidade fundada sobre as ribeiras do Tejo”, que identifica com Almourol (p. 332). 


\section{O CONTEXTO HISTÓRICO E ARQUEOLÓGICO}

Baseando-se nas fontes históricas disponíveis a que atrás se aludiu, frei Bernardo de Brito ajuntou mais uns pormenores que se lhe afiguraram susceptíveis de tornar a sua narrativa verosímil, nomeadamente se tivermos em conta que parte das campanhas de Júnio Bruto não terão sido contadas. $\mathrm{O}$ contexto histórico é, todavia, bem claro: as lutas de Romanos contra os povos que habitavam esta zona ocidental da Hispânia e que, para o frade, eram os "Portugueses".

No caso das epígrafes e dado que vamos debruçar-nos, a título de exemplo, sobre a segunda referida, crê-se não ser descabido pensar que frei Bernardo de Brito - aliás, como se viu pela descrição - não terá escolhido ao acaso o cenário onde situou esta batalha. Cumpre, por conseguinte, interrogar-nos: temos notícia, em Vide, das duas ermidas de que se fala, a de S. João Baptista e a de S. Sebastiáo? Registam-se, no seu termo, vestígios arqueológicos passíveis de se atribuir à época romana?

O caminho mais fácil foi, naturalmente, o recurso ao Roman Portugal, de Jorge Alarcão (1988a), manancial imprescindível.

Por exemplo, sob o n. $4 / 53$ (p. 54 do vol. II, fasc. 1), assinala-se que em Vide, da freguesia de Rua, concelho de Moimenta da Beira, refere João Vaz (1982) a existência de "vestígios romanos não especificados" e alude Gonçalves da Costa (1979: 140-141) ao facto de se ter noticiado que, "em local impreciso, entre Vide e Granja de Oleiros", se detectaram "alicerces, cerâmica de construçáo e doméstica, pesos de tear, moedas". Em Moimenta da Beira (é o n. o 4/50) achou-se ocasionalmente cerâmica romana do século I d. C.; na Aldeia de Nacomba, um "troço de estrada romana com cerca de $1 \mathrm{~km}$ de extensáo" (n. ${ }^{\circ}$ 4/51); em Caria mantemo-nos no termo do concelho de Moimenta - um miliário, um "tesouro de denários de composição e cronologia desconhecidas", cerâmica (n.o 4/52); no Monte Coutado, pertencente à freguesia de Caria, outro "tesouro de denários cuja composição e cronologia se desconhecem" (n. $\left.{ }^{0} 4 /\right)$; em Rua, além de "vestígios romanos, náo especificados", achou-se "um vaso de barro com lingotes de prata e denários que foram dispersos sem terem sido estudados" (n.o 4/54); de Prados (freguesia de Rua) procede a inscrição CIL II 427 (n.o 4/55) e de Quinta da Lagoa, da mesma freguesia, as inscriçóes CIL II 4642 e 4643; de S. João, 
ainda na mesma freguesia, um "tesouro de moedas de cobre cuja composição e cronologia se desconhecem" (n. $\left.{ }^{0} 4 /\right)^{2}$.

Embora parte significativa destes achados tenha sido feita, naturalmente, num período posterior ao da obra de frei Bernardo de Brito, náo pode, por conseguinte, afirmar-se que o frade não tenha tido conhecimento de que algo de romano por ali se encontrara e que, por isso, a escolha do sítio para localizar a paragem de Décimo Júnio Bruto não pode ser interpretada como rematado despropósito. E a caça aos tesouros da nossa época é eco do que Bernardo de Brito conta: "[...] os lavradores, que ali vinham cavar, com esperança de achar algum dinheiro [...]”. Na verdade, abundam os vestígios da época romana nessas paragens.

Vejam-se, por exemplo, as três inscriçóes citadas.

Comecemos pela última: CIL II 4643 (Fig. 3):

Hübner reproduz as informaçóes de Bernardo de Brito e assinala que também Viterbo (I: 238) se lhe refere ${ }^{3}$, mencionando-a como existente "em Vide, no frontispício da capela do Espírito Santo", o que foi confirmado por Alexandre Canha, que fez a respectiva foto (Fig. 4). A leitura é:

\section{BONO REI}

PVBLICE

NATO

2 Em 2004 (p. 332), com vista a uma possível localização de Omnia, Jorge de Alarcão enumera de novo os achados aqui referidos, especificando-os um pouco mais.

3 Citam-se as informaçōes relativas a Viterbo, náo obstante da consulta feita à 2. a edição do Elucidário citada na bibliografia, disponibilizado na página da Biblioteca Nacional de Portugal, ter resultado que as epígrafes são referidas, s. v. "Caria", na p. 164 do tomo I. Viterbo descreve a inscrição da capela de S. Domingos com tal pormenor que daí se deduz tê-la visto. 
4643 'Llecada das ruinas do junto a emida de S. Joāo", servata "no puredo da ermida de S. Sebantiâo an Vide" Britto. 'En Vide, no frontippicio da copella do Eupirito Santo" Tit.

$$
\begin{aligned}
& \text { DONO } \\
& \text { NEIP } \\
& \text { NATO }
\end{aligned}
$$

Britto ed. I 1 f. 254, ed. IT 1 p. 332; Viterbo 1, 238.

Diversa a pracedente.

Fig. 3

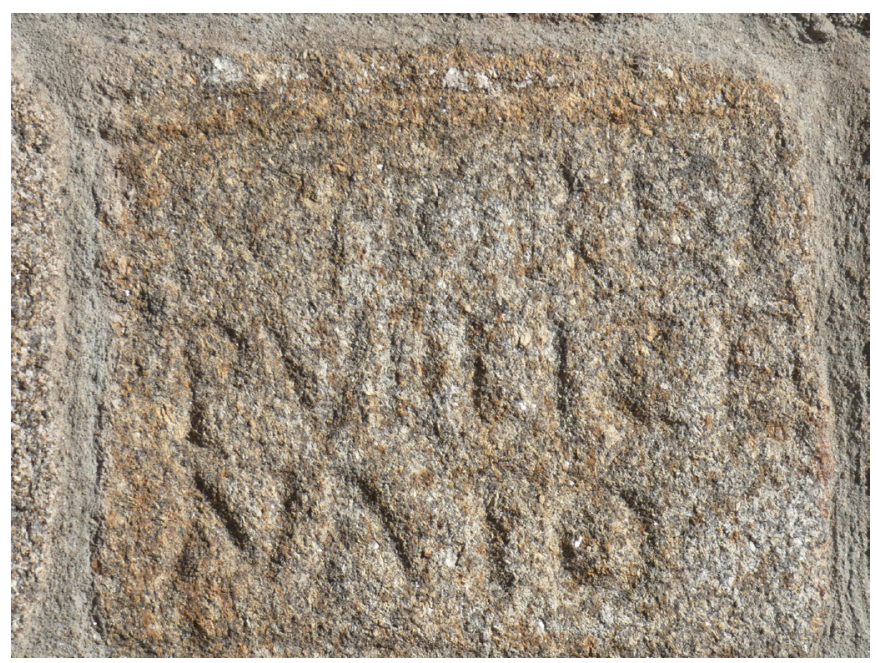

Fig. 4 
Significa, como se sabe, "Ao nascido para o bem da República" e constitui, portanto, solene elogio. Pode surgir isolado numa base, como é o caso, ou - o que é mais frequente - no final dos miliários, nomeadamente a partir do século III (Bellezza, 1996: 90), aplicado quase em exclusivo aos imperadores.

Trata-se de inscrição predisposta, digamos assim, a ser colocada numa via; vestígios de vias e de miliários não faltam, aliás, na regiáo, por onde passaria a via imperial que ligava Viseu, capital de civitas, a Paredes da Beira (S. João da Pesqueira), eventual capital (a dos Arabrigenses?), e às civitates a norte de Douro, em torno de Chaves (Mantas, 2012: 245); a passagem desta via justificará também, como foi sugerido, "a densidade e a importância dos achados nessa zona, em particular de Moimenta da Beira”. Virá, pois, a propósito referir que CIL II 4642 é o texto de um miliário identificado, segundo Viterbo (I: 238), "em 1788, na Quinta da Lagoa, perto de Vide"; para além de algumas letras de significado ininteligível, que Hübner reputa modernas ou apócrifas, trazia a expressão fortissimo Caes(ari), que nos remete, de modo especial, para os primórdios do século IV, sendo muito frequente em homenagens a Constâncio e a seu filho Constantino.

CIL II 427 (Fig. 5) é uma inscrição funerária que, segundo Viterbo (I: 329), também teria sido encontrada em 1788, em Prados (Caria), "junto a villa de Rua, no frontispício da capella de S. Domingos”.4.

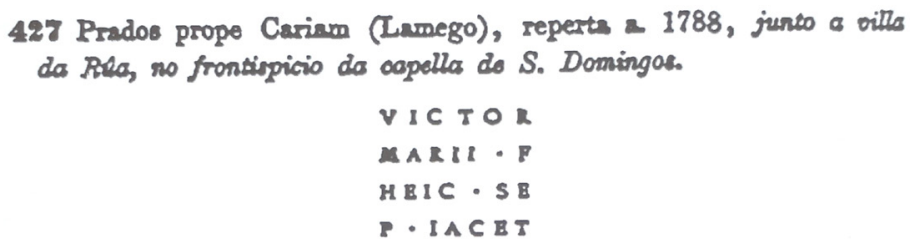

Viterbo 1, 329 (inde Caldes p. 14; e Caldes Lory 291, 702), e cuina achedis mibi minit Berarda.

Fig. 5

\footnotetext{
4 Hübner localiza esta Caria no território de Lamego; lapso compreensível por ser este topónimo assaz frequente e haver, de facto, várias localidades com este nome.
} 
Não se trata, todavia, de epígrafe com um texto usual:

\section{VICTOR / MARII F(ilius) / HEIC SE/P(ultus) IACET \\ Vitor, filho de Mário, aqui jaz sepultado.}

Este é um dos casos em que o epigrafista - se também não é dado observar a paleografia - hesita, ao lembrar-se do caso que Amílcar Guerra deu a conhecer (1989: 425-426): alguém que se identifica de uma forma que, à partida, faríamos remontar aos primórdios dos tempos romanos na Lusitânia (nome único e filiação: Vegetus Talabarif.), mas cuja inscrição está datada pela menção dos cônsules de $217 \mathrm{~d}$. C. Apontar-se-ia, à primeira vista, para a 1. a metade do século I, atendendo ao modo de expressar a identificação e também ao aparente arcaísmo heic por hic. Há, no entanto, a meu ver, indícios que não se enquadram nessa cronologia, para além da onomástica perfeitamente latina:

a) O "arcaísmo" pode ser, como disse, aparente, uma forma de querer manifestar antiguidade, como, hoje em dia, amiúde se utilizam grafias antigas (Vasconcellos, Thomaz) só para dar algum toque de... originalidade!

b) O erudito heic sepultus iacet, em vez do mais comezinho hic situs est, sugere passagem para um outro horizonte cultural, mais requintado e literário, a antecipar, dir-se-ia, os formulários das primeiras comunidades cristâs.

Uma datação de finais do século III ou mesmo do IV século não se me afigura nada aberrante e concorda, por outro lado, com a maior parte dos vestígios por ali encontrados, designadamente os miliários 5

\footnotetext{
5 Agradeço a Amílcar Guerra a opinião que gentilmente partilhou: "A decisão de uma dataçấo tardia está perfeitamente certa, na minha perspectiva. Talvez até mais avançada. Fiz uma simples pesquisa no EDCS de inscriçóes em que ocorre simultaneamente sepultus/a e iacet e a impressão que colhi é que, geralmente, se trata de inscriçōes tardias (muitas vezes apenas com nome único e patronímico), algumas delas cristãs".
} 
Análise feita com base na documentação escrita, importava saber se o letreiro continuava onde fora referido por Bernardo de Brito. Graças ao pronto empenho de Alexandre Canha, que muito agradeço, confirmou-se o paradeiro; como, no entanto, já entáo - como hoje! - o monumento teria pouca visibilidade, a leitura do frade foi... parcialmente inventada! Não obstante o estudo levado a cabo, adiante-se desde já a leitura das três primeiras linhas desta longa estela de granito, de topo semicircular, datável da $1 .^{\text {a }}$ metade do século I, leitura só tornada possível mediante a utilização, por Alexandre Canha, de técnicas fotográficas digitais específicas:

$$
\text { VEGETVS / MARI }(i) \cdot \mathrm{F}(\text { ilius }) \cdot / \mathrm{H}(\text { ic }) \cdot \mathrm{S}(\text { itus }) \cdot \mathrm{E}(\text { st }) /[\ldots]
$$

Ou seja: o patronímico é, de facto, Marius, mas o defunto não se identifica através de um nome latino, mas sim com um antropónimo comum entre a comunidade indígena da Lusitânia, Vegetus. Pode adiantar-se que é bem diferente da proposta por Bernardo de Brito a leitura das linhas seguintes (cf. Canha, Encarnação; Santos, 2018).

\section{A EPÍGRAFE CIL II 55*}

Não admira, pois, que - ou por experiência própria, como dá a entender, ou porque testemunhas lhe falaram do que se via e a cada passo se lhes deparava - frei Bernardo de Brito náo haja hesitado em contar que ali mesmo assentou arraiais Décimo Júnio Bruto e ripostou a custo contra os "Portugueses". E, como prova de como fora dura a refrega, dois epitáfios o procônsul mandara gravar em honra de dois dos seus valorosos soldados: um porta-estandarte (signifer) e um cavaleiro. Debrucemo-nos sobre o do cavaleiro, para se esmiuçarem técnicas e argúcias.

Antes, contudo, importa reflectir: seria verosímil que Bruto se tivesse preocupado em mandar gravar uma epígrafe, por mais rápido que fosse o canteiro e o lapicida, se é que algum deles poderia estar integrado no seu corpo de tropas? Creio que não, não é verosímil e, a partir daqui, não valeria a pena terçar armas em prol da invençáo. Talvez valha, no entanto, com o propósito de se analisar melhor a estratégia usada para dar verosimilhança à narrativa, aproveitando-se 
não apenas para afirmar que Bruto sofrera duas baixas pesadas (o signifer detinha grande valor simbólico, como se sabe), mas também para enaltecer (e isso era o que mais interessava) a bravura com que os "Portugueses" se haviam batido, a ponto de terem fortemente desfalcado as tropas inimigas.

Anote-se, ainda, que houve, da parte de Brito, um cuidado especial para garantir a autenticidade: a pedra estava "na ermida velha de $S$. João" e "servia de assento dentro" dela. Além disso, enquanto das outras epígrafes também Viterbo fez eco, desta nada diz.

Desdobrem-se, então, siglas e abreviaturas (raras são as que seguem os cânones habituais da pura linguagem epigráfica e, por isso, também a sua decifração constitui atraente desafio para o epigrafista...), mais com base, portanto, no que a tradução de Bernardo de Brito pretendeu comunicar:

\section{$\mathrm{D}$ (is) M(anibus) S(acrum) / G(aius) POSIDONIUS EQUES ROM(anus) / MONTIS VIM(inalis) IN VICTORES / BARBAROS INCITAT(us) EQUO / EVECT(o) FORT(i)T(er) OCCUB(uit) D(ecimus) I(unius) BRU- $\mathrm{T}($ us ) / $\mathrm{A}$ (more) $\mathrm{B}$ (enevolentia) $\mathrm{Q}($ ue $) \mathrm{C}$ (ompulsus) $\mathrm{H}($ oc $) \mathrm{M}$ (onumentum) $\mathrm{AP}$ (parandi) $\mathrm{C}$ (uravit) $\mathrm{S}($ it) $\mathrm{T}($ ibi) $\mathrm{T}($ erra $) \mathrm{L}$ (evis)}

"Consagrado aos deuses Manes. Gaio Posidónio, cavaleiro romano, do Monte Viminal, impelido contra os bárbaros vencedores, tendo o cavalo arremetido fortemente, sucumbiu. Décimo Júnio Bruto, levado pelo amor e pela benevolência, tratou de aparelhar este monumento. Que a terra te seja leve".

Trata-se, obviamente, de uma proposta de restituição, em que - por exemplo, no caso de occubuit, compulsus, apparandi - outras soluçóes se poderiam apresentar.

1. Antes de se tecerem consideraçóes acerca do texto, importa atentar na ficha, que se reproduz (Fig. 6), de CIL II 55* (p. 9*): Hübner transcreve exactamente o que leu em Bernardo de Brito, acrescentando que o frade afirma ter visto o letreiro e dá conta de que também Levy Maria Jordão o copiou, sem mais (p. 212, inscrição n. ${ }^{\circ} 480$ ). 


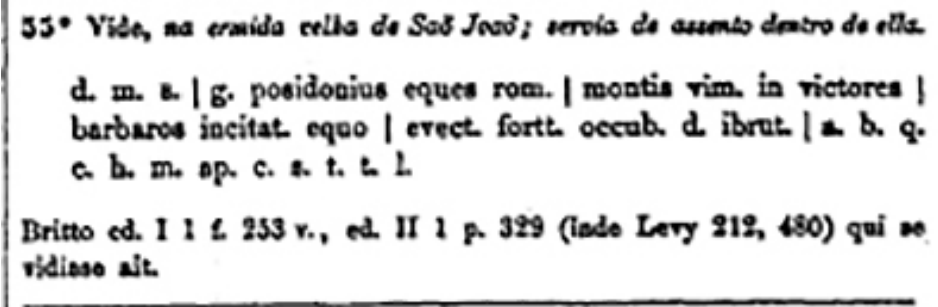

Fig. 6

2. Tanto a consagração inicial aos deuses Manes como o desiderato final "que a terra te seja leve" só aparecem nos textos funerários da Lusitânia romana a partir da 2. a metade do século I d. C., sendo comuns no decorrer do século II. Isso desconheceria Bernardo de Brito; doutra forma, não os incluiria numa epígrafe supostamente datada da segunda metade do século I a. C. Desconhece igualmente o valor da pontuação epigráfica - para separar as palavras e não para assinalar abreviaturas, como o fez.

3. Posidonius, aqui apresentado como nomen, está atestado (com dois SS) em Mértola, a identificar um presbiter (HEpOL 1700, AE 1985. 506); CIL II 496719b seria grafito em ladrilho encontrado em Hispalis, mas Hübner acha que se trata de um apócrifo; CIL II 496719a traz Posidoni. Na base de dados EDCS, Possidonius surge tanto como nomen como cognomen, no masculino e no feminino; contudo, é Posidonius (com um só S) que tem quase uma centena de testemunhos, a identificar indivíduos das mais diversas classes sociais. Solin (1982: 295-296) inclui-o entre os nomes etimologicamente gregos e, na epigrafia de Roma, inventariou 33 testemunhos, dos quais 8 como nomes de escravos e/ou libertos.

Não admira que Bernardo de Brito o tenha escolhido, pois foi esse o nome do filósofo grego, Posidónio de Apameia (135 a. C. - 51 a. C.), a que Cícero se referiu em termos elogiosos ${ }^{6}$ e Séneca virá também a ter em consideração, citan-

6 "Quod eo magis miror quia scriptum a discipulo eius Posidonio est triginta annis uixisse Panaetium posteaquam illos libros edidisset. Quem locum miror a Posidonio breuiter esse 
do-o amiúde, especialmente nas Ad Lucilium Epistulae Morales, donde retiro, a título de exemplo, as frases:

- "Nam ut Posidonius ait unus dies hominum eruditorum plus patet quam imperitis longissima aetas" $(78,28)$;

- "Posidonius ut ego existimo melius qui ait diuitias esse causam malorum non quia ipsae faciunt aliquid sed quia facturos inritant" $(87,31)$;

- "Hoc loco tibi Posidonii nostri referre sententiam volo [...]" $(113,28)$.

Leitor, obviamente, de Séneca, frei Bernardo de Brito certamente se deixou também seduzir pelo apreço em que o filósofo latino tinha Posidónio. E, para o 'seu' cavaleiro, heroicamente morto em combate, outro nome de tamanho significado náo poderia haver.

3. O facto de se dizer que Posidónio era "do Monte Viminal" nada mais significa do que afirmar ser oriundo de Roma. O Monte Viminal era uma das sete colinas da cidade, sem nenhum significado específico. Não surge nos monumentos epigráficos como Monte, na conotaçáo de naturalidade ou de morada, mas sim como collis, 'colina'. Assim: L(ucius) Titinius foi mag(ister) vici col(lis) Vimin(alis) (CIL VI 2228) e um liberto é dito de colle Viminale (CIL VI 9499).

4. Victores barbari: os barbari são os "Portugueses" adversários de Bruto; o facto de serem apresentados como victores, "vencedores", realça o que o frade queria dizer: os "Portugueses" estiveram a ganhar e foi por isso necessário reforçar as hostes; no entretanto, este cavaleiro sucumbiu.

5. "Incitare equos" é frase corrente: meter esporas neles! São muitos os testemunhos literários do uso deste verbo, ainda que esteja ausente, quanto sabemos, dos monumentos epigráficos. No caso vertente, pelo facto de se usar, para o cavalo, um ablativo absoluto (equo evecto), a possibilidade de ter havido uma 'contaminaçáo' afigura-se-me viável, porque, na verdade, tanto cavalo como cavaleiro se lançaram contra os inimigos!...

tactum in quibusdam commentariis praesertim cum scribat nullum esse locum in tota philosophia tam necessarium" (Cícero, De Officiis, 3, 8, 2-3). 
6. Raramente usado, o termo evectus surge em duas expressôes equivalentes da epigrafia da cidade de Roma, no sentido de "lançado para": "[...] ad columen gloriae sempiternae et regiae adfinitatis evecto" (CIL VI 31 913a) e "[...] clarissimae militiae ad columen regiae adfinitatis evecto socio [...]" (CIL VI 31 913b). Evectio era a permissão para obter cavalos de posta e todo este contexto encerra a ideia de agarrar num cavalo e lançá-lo ao ataque. Dos textos clássicos citem-se "Nunquam ego evectionem datavi quo amici mei per symbolos pecunias magnas caperent" (Catão, Orationum Fragmenta, 173, 15) e de Séneca (Hercules Furens, 132): "Iam caeruleis euectus equis Titan summa prospicit Oeta..." ("Já, lançado com os seus cerúleos cavalos, Titã contempla de longe o elevado Eta...”).

7. $\mathrm{O}$ verbo occubare é também de uso raro em Epigrafia; náo chegam às duas dezenas os testemunhos encontrados quer nos textos da época romana quer já em textos cristáos. Respigo de EDCS:

Num carmen da Etrúria, datável de 351-430 (CIL XI 2839), proclama-se que Castorius "occubat in terris sapiens sed vivit in astris", "jaz sepultado na terra, mas vive nos astros". Num outro poema, da época cristã (EDCS - 38302439), se declara que Felix "conspicuus vixit, flebilis occubuit". E o martírio de Paulo é descrito desta forma: "Laetior occubuit Paulus cervice secanda" (EDCS - 33900278).

Já em Séneca (Phaedra, 997), o verbo estava conotado com uma morte que profundamente se lamentava, porventura devido a circunstâncias desagradáveis: "Hippolytus heu me flebili leto occubat", "Hipólito, ai de mim, de funesta morte sucumbe".

8. Apparare, neste sentido de 'preparar cuidadosamente', não é do domínio epigráfico; podem apresentar-se exemplos retirados dos autores clássicos: "reliquum diei apparandis armis consumptum est" (Lívio, 3, 62, 5), 'o resto do dia foi passado a preparar as armas'; "cenam apparare" (Terêncio, O homem que se puniu a si mesmo, 126); "ornare et apparare convivium" (Cícero, In C. Verrem actio secunda IV 44, 12). 


\section{CONCLUSÃO}

É claro o intuito de frei Bernardo de Brito em forjar esta epígrafe: mostrar como, perante o invasor romano, os indígenas - que, para ele, são, obviamente, os Portugueses - bravamente se bateram, chegando a provocar a morte de um signifer e de um eques Romanus, título aqui usado adequadamente, porque amiúde registado na epigrafia romana?.

Terá sido 'cirúrgica', diríamos, a escolha do lugar para situar uma dura refrega entre Lusitanos e Romanos: de facto, toda essa região a sul de Moimenta, banhada pelo rio Távora, está cheia de vestígios da época romana, como se disse. Quer a conhecesse de visu, por eventualmente a ter visitado, quer porque testemunhas oculares dela lhe falaram, o certo é que, pelo menos, duas inscriçóes estão lá, como o frade assinalou.

Esta, sem dúvida, a primeira conclusão a tirar: há que desconfiar sempre, quando um autor antigo, por menos credibilidade que aparentemente nos mereça, localiza um facto histórico, designadamente do tempo dos Romanos! É que rara será a ocasião em que se não encontrem aí, de facto, vestígios dessa época.

E a segunda conclusão prende-se com a sabedoria que está por detrás dessa atitude: atendendo à existência de documentos verdadeiros, náo haveria perigo de se levantarem perplexidades!... Há aí inscriçôes autênticas? Porque não imaginar, entâo, algumas outras, que sirvam os nossos interesses patrióticos, de exaltação da valentia dos "Portugueses" contra o invasor, numa altura (recorde-se) em que urgia continuar a luta contra os Espanhóis, que nos haviam usurpado o poder?... Importava revigorar o entusiasmo, recordar exemplares epopeias ancestrais, as façanhas dos nossos heróis! Neste caso, o "herói” é anónimo, é o Povo - porque, na verdade, o que interessa não é uma alusão concreta, mas sim o feito de todos, em união, uma união que ora se requeria também.

A análise epigráfica apresentada permite-nos, além disso, verificar como frei Bernardo de Brito, não sábio das epigráficas letras, mas mestre nas letras dos

\footnotetext{
Tem sido, por exemplo, bastante reproduzido o magnífico baixo-relevo de homenagem a T(ito) Flavio T(iti) f(ilio) Pal(atina) Vero equiti Romano, achado em Óstia (CIL XIV 167; AE 1961, 259).
} 
autores antigos que miudamente compulsara, soube entrelaçar o que sabia (as fórmulas iniciais e as finais, nomeadamente, estavam bem patentes em muitíssimas epígrafes) com o que lera e ajustar tudo, de forma a dar a maior verosimilhança possível. Sabe que H. M. são as habituais siglas de hoc monumentum, C por curavit também é comum; prefere, todavia, não o vulgar faciendum curavit, mas, para dar maior realce ao acto, apparandi curavit, porque, não há duvida, apparare é mais empenhativo e pessoal.

Claro que nem sequer se pôs a questão se Décimo Júnio Bruto levava canteiros na sua comitiva e se poderia dispor de tempo para mandar lavrar epitáfio tấo complexo. Era, confessemos, uma questão de somenos. Quem se iria preocupar com isso? Não estava ali uma declaração de derrota? Apesar de barbaros para esse estrangeiro, não tinham sido (ele próprio o declarava!...) os Portugueses victores, 'vencedores'? Para quê levantar, então, mais questôes?

Não pode o concelho de Moimenta da Beira orgulhar-se de ter no seu espólio arqueológico esta bem solene inscrição, porque nunca chegou a existir a não ser na imaginação de um erudito freire alcobacense; no entanto, o facto de ele ter fingido que a encontrara ali mostra apreço por uma terra onde, na verdade, os vestígios romanos superabundam. E, no fundo, nem é precisa esta inscrição!

\section{BIBLIOGRAFIA}

$\mathrm{AE}=$ L'Année Épigraphique. Paris: Presses Universitaires de France.

Alarcão, J. (1988a). Roman Portugal. Warminster: Aris and Phillips, Ltd.

(1988b). O domínio romano em Portugal. Mem Martins: Publicações Europa-América.

(2004). Notas de arqueologia, epigrafia e toponímia - II. Revista Portuguesa de Arqueologia, 7(1), 317-342.

Bellezza, Angela Franca (1996). Bonum rei publicae fra epigrafia e storiografia nella tarda antichità. Spunti e riferimenti. In Clara Stella; Alfredo Valvo (Coords.), Studi in onore di Albino Garzetti (73-95). Brescia: Ateneo di Brescia.

Brito, Frei Bernardo (1690). Monarchia Lusytana [...], parte I. Lisboa: Impressão Craesbeeckiana. Canha, Alexandre; Encarnação, José d'; Santos, José Carlos (2018). CIL II 427 revisitada. Ficheiro Epigráfico 179, inscrição no 677.

$\mathrm{CIL}=$ Corpus Inscriptionum Latinarum. Berlim: Academiae Litterarum Borussicae. 
CIL II = Hübner, Emil (1869, 1892), Corpus Inscriptionum Latinarum - II. Berlim: Academiae Litterarum Borussicae.

Costa, M. Gonçalves da (1979). História do bispado e diocese de Lamego, II. Lamego.

EDCS = Epigraphik Daten-bank Claus / Slaby.

Encarnação, José d' (1969). Os diálogos do sítio de Lisboa, de Luís Mendes de Vasconcelos. Olisipo, 125-126, 37-51.

Guerra, Amílcar (1989). Uma importante epígrafe proveniente do Cabeço do Crasto (S. Romão, Seia). Actas do I Congresso Arqueológico de Viseu (425-430). Viseu: Governo Civil.

$\mathrm{HEpOL}=$ versão on-line de Hispania Epigraphica. Universidade Complutense de Madrid.

Mantas, Vasco Gil (2012). As vias romanas da Lusitânia. Série Studia Lusitana n. ${ }^{\circ}$ 7. Mérida: Museo Nacional de Arte Romano.

Solin, Heikki (1982). Die griechischen Personennamen in Rom. Ein Namenbuch. Berlin, New York: Walter De Gruyter \& Co.

Vaz, João L. Inês (1982). "A estrada do bispo Alves Martins" velha estrada romana?. Beira Alta 41 (4), 781-792.

Viterbo, Frei Joaquim de Santa Rosa de (1744-1822). Elucidário das palavras, termos e frases que em Portugal antigamente se usaram [...]. Lisboa: A. J. Fernandes Lopes [2. ${ }^{\mathrm{a}}$ ed. datada, por lapso, de MCCCLXV, sendo, naturalmente, 1865].

[texto escrito no antigo acordo] 